\title{
Expression of MAGE-A1-A12 subgroups in the invasive tumor front and tumor center in oral squamous cell carcinoma
}

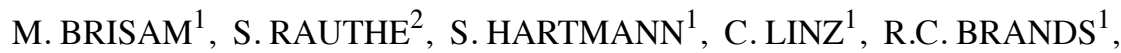 \\ A.C. KÜBLER ${ }^{1}$, A. ROSENWALD ${ }^{2}$ and U.D. MÜLLER-RICHTER ${ }^{1}$ \\ ${ }^{1}$ Department of Oral and Maxillofacial Plastic Surgery, University Hospital Würzburg, D-97070 Würzburg; \\ ${ }^{2}$ Institute of Pathology, University Würzburg, D-97080 Würzburg, Germany
}

Received August 4, 2015; Accepted September 23, 2015

DOI: $10.3892 /$ or. 2016.4600

\begin{abstract}
MAGE-A proteins are highly expressed in oral squamous cell carcinoma (OSCC) and are promising targets for cancer immunotherapy. This study examined the presence of MAGE-A expression within the tumor center (TC) and tumor invasive front (TIF) and evaluated its relationship to poor prognosis. The expression rate of each MAGE-A subtype, A1-A12, was examined in 68 OSCCs at the TIF and TC. Slides $(1-\mu \mathrm{m})$ of tissue microarrays $($ diameter $=0.6 \mathrm{~mm})$ were immunohistochemically stained, and the findings were correlated to clinical data. Approximately $95 \%$ of the tumors had MAGE-A expression. Higher expression in the TC was shown significantly for MAGE-A1, -A5, -A6, -A9 and -A12 $(\mathrm{P}<0.05)$. MAGE-A2 and -A3 exhibited the opposite behavior (not significant, $\mathrm{P}>0.05$ ). Age, tumor size, grade and survival time were not associated with the expression of certain MAGE-A subgroups. When expression in the whole tumor tissue was considered, only MAGE-A1 was expressed at a significantly higher rate in male patients $(\mathrm{P}=0.034)$. At the TIF, MAGE-A9 and the UICC disease stage were significantly correlated $(\mathrm{P}=0.0263)$, and MAGE-A6 and the UICC disease stage exhibited a strong trend $(\mathrm{P}=0.0596)$. The expression of MAGE-A3, -A4, -A5, -A9 and -A11 was significantly associated with lymph node metastasis, while MAGE-A4 was expressed in all regions of the tumors (TIF and TC). This study showed that higher expression of most MAGE-A antigens occurred at the TC rather than at the TIF. MAGE-A1, -A3, -A4, -A5, -A9 and -A11 were significantly associated with clinically advanced stages of disease and seem to be of particular interest.
\end{abstract}

Correspondence to: Dr U.D. Müller-Richter, Department of Oral and Maxillofacial Plastic Surgery, University Hospital Würzburg, Pleicherwall 2, D-97070 Würzburg, Germany

E-mail: mueller_u2@ukw.de

Key words: cancer/testis antigens, oral squamous cell carcinoma, tumor center, tumor invasive front, MAGE-A antigens

\section{Introduction}

Oral squamous cell carcinoma (OSCC) has a poor prognosis and outcome. It is one of the six most common types of cancer, with an annual incidence of $>300,000$ cases worldwide (1-3). Although cancer therapy has improved within the last three decades (particularly advanced radiotherapy with or without chemotherapy and enhanced surgical procedures), the prognosis remains poor, with an average 5-year survival rate of $55 \%(1,4,5)$. Promising immunotherapies that use specific antigen-antibody interactions may diminish this disappointing outcome. MAGE-A antigens are only expressed in certain cancer cells, fetal tissue, placenta and testis but not in healthy tissue, except in the thyroid where it is expressed only to a small degree (6). MAGE-A antigens belong to MAGE antigen group I, a type of cancer/testis antigen (CTA) that is localized on the $\mathrm{X}$ chromosome and appears to play a key role in tumorigenesis in many types of cancer, including those of the head and neck $(7,8)$. MAGE-A1, which is the first type of antigen recognized by cytotoxic $\mathrm{T}$ lymphocytes, marks the first of these subtypes. The remaining subtypes A2-A12 (with the exception of MAGE-A7, which presents itself as a pseudogene) all appear to be interesting immunogenic markers that could be used for cancer therapy (8). Their expression has been described for several types of tumors, such as breast carcinoma, non-small cell lung cancer and squamous cell carcinoma of the head and neck (9-11). Several authors have suggested that MAGE-A antigens are associated with the development and maintenance of aggressive characteristics in tumors $(12,13)$. Therefore, these antigens could represent tools to improve the diagnosis, therapy and prognosis of OSCC. Recently, a cocktail of more than five MAGE-A subgroups (stained by the antibody MAGE57B) was shown to have interesting expression rates in OSCC (14-19). Therefore, the detailed expression of each subtype is now of particular interest and should be determined. The rates for each MAGE-A subtype in OSCC were investigated in this study. Furthermore, the differences in the tumor center and invasive front were examined. Previous studies have described different characteristics of cells in the center and at the invasive front of the same tumor. These studies showed that there were higher mutation rates of p53 or kinase-inhibitor $\mathrm{p} 21$ and a higher rate of cell proliferation at the invasive front (20-22). Expression rates of MAGE-A antigens 
at different tumor sites could have clinical value as indicators of high progressive tumor growth, guiding the switch to more radical therapeutic strategies or the generation of individual patient protocols. Hartmann et al have already investigated the efficacy of chemotherapeutics on tumor cell lines that expressed several MAGE-A types (23) and also evaluated the use of monoclonal antibodies such as cetuximab and panitumumab (24). Their investigations clarified the need to even more precisely identify the particular MAGE-A subtypes that influence the failure of chemotherapy and immune therapy in OSCC.

\section{Materials and methods}

Patients and tissue microarrays. The pathological samples for this study were selected from the archives of the Department of Pathology of the University of Würzburg, Germany. Sixtyeight paraffin-embedded OSCCs with clear evidence of invasive fronts at the deep surface of the biopsy were chosen. The anatomic source of the biopsy specimens included the tongue, lip, tonsil, cheek, palate, oropharynx and other sites of the oral cavity, but no sites with respiratory epithelia. The mean age of the patients at diagnosis was 56.85 years (SD: 13.0 years), and the study sample included 51 males and 17 females. Twenty-seven tumors were stage T1, 17 were stage T2 and 21 cancers were stage T3 or higher. The staging for 3 samples was not evaluable (Table I).

From each case, a representative block was retrieved, and tissue microarrays (TMAs) of the tumor invasive front and the tumor center were constructed such that each case was represented by three $0.6 \mathrm{~mm}$ cores (Fig. 1). One-micron-thick sections were cut and mounted on saline-coated slides.
Table I. The patient specimens: Separate examination of the different clinical parameters was performed due to the heterogeneous retrospective data.

\begin{tabular}{ccccc}
\hline & T1 & T2 & T3 & T4 \\
\hline \multirow{4}{*}{$\mathrm{n}=65$} & 27 & 17 & 9 & 12 \\
& N0 & N1 & N2 & \\
$\mathrm{n}=52$ & 36 & 9 & 7 & \\
& UICC 1 & UICC 2 & UICC 3 & UICC 4 \\
$\mathrm{n}=65$ & 25 & 13 & 12 & 15 \\
\hline
\end{tabular}

n, number of valid cases; T1-4, T-stages; N0-N2, lymph node status; UICC1-4, disease stage.

Immunohistochemical staining. As a positive control for immunohistochemical staining, normal adult testis tissue was used. As negative controls, either healthy lung tissue or testis without the use of secondary antibodies was used. One-micron-thick sections of the TMAs were cut and mounted on saline-coated slides. Phosphate-buffered saline (PBS) was used as the diluent for washing and rinsing steps throughout the immunohistochemistry protocol, except for the purposes of antigen retrieval. The antibodies of MAGE-A1-A12 were diluted as shown in Table II.

The TMA sections were deparaffinized, rehydrated and subjected to antigen retrieval by autoclaving for $15 \mathrm{~min}$ in individually tested buffer saline as shown in the Table II. The sections were incubated with primary antibody for $1 \mathrm{~h}$ at room
A
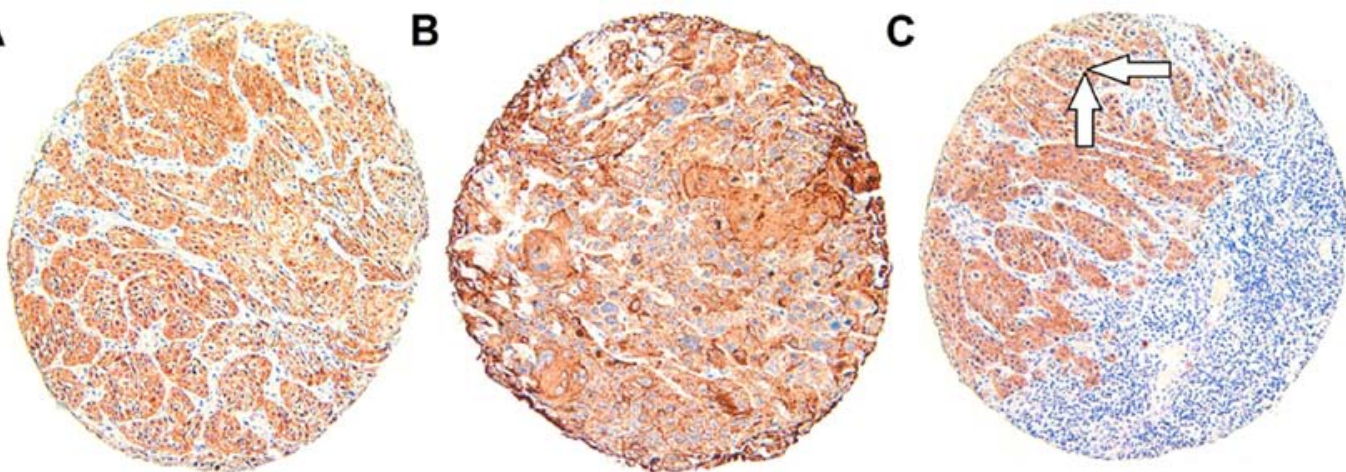

D

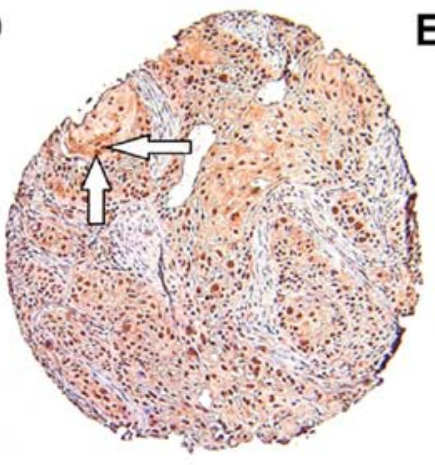

E

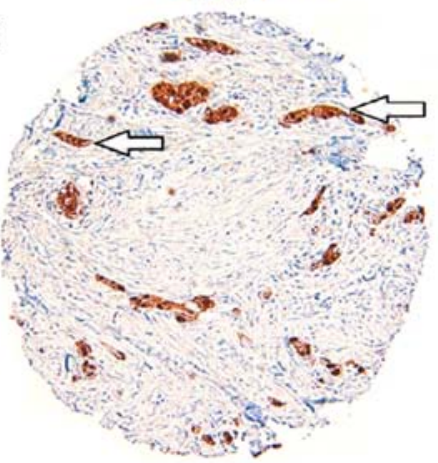

$F$

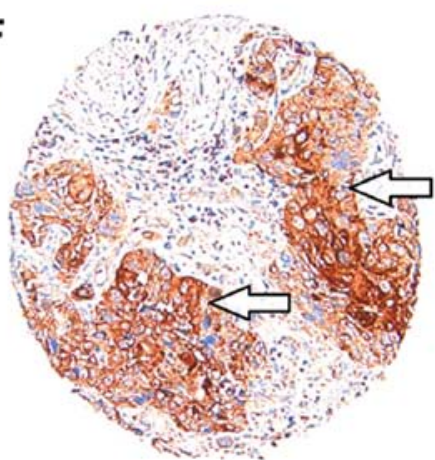

Figure 1. Expression of MAGE-A antigens in invasive oral squamous cell carcinoma. Examples of positive staining (A-F). For most MAGE-A antigens in this study, mainly cytoplasmic staining is shown (C), although nuclear and cytoplasmic staining together can also be observed (D). Although squamous cell carcinomas often have diffuse expression of special antigens within a tumor, focal expression is not uncommon (E and $\mathrm{F}$ ). (Magnification, $\mathrm{x} 50$ ). 
Table II. Origin, dilution and source of the MAGE-A antibodies used in the study.

\begin{tabular}{|c|c|c|c|c|c|}
\hline Antigen & Origin & Code & Heat buffer & Dilution & Source \\
\hline MAGE A1 & Rabbit & $\begin{array}{l}\text { Cat \# RP 144, 144-05, } \\
\text { Lot \# 066N, } \\
\text { ABIN125659 }\end{array}$ & CA & $1: 100$ & Antibodies online (Aachen, Germany) \\
\hline MAGE A2 & Rabbit & $\begin{array}{l}(\mathrm{N}-18) \mathrm{sc}-130164 \\
\text { Lot \# D0209 }\end{array}$ & TR & $1: 20$ & $\begin{array}{l}\text { Santa Cruz Biotechnology, Inc., } \\
\text { Dallas, TX, USA }\end{array}$ \\
\hline MAGE A3 & Rabbit & $\begin{array}{l}\text { NBP-1-02506 } \\
\text { Lot \# } 20930\end{array}$ & CA & $1: 100$ & Novus Biologicals (LLC, CO, USA) \\
\hline MAGE A4 & Rabbit & $\begin{array}{l}\text { Cat \# PAB 4746, } \\
\text { Lot \# SH030122L }\end{array}$ & TR & $1: 40$ & Abnova, Taipei City, Taiwan \\
\hline MAGE A5 & Rabbit & $\begin{array}{l}\text { Cat \# PAB-10795 } \\
\text { Lot \# RB } 2085\end{array}$ & $\mathrm{CA}$ & $1: 100$ & $\begin{array}{l}\text { Antibodies online (Aachen, Germany), } \\
\text { www.allele.biotech.com }\end{array}$ \\
\hline MAGE A6 & Rabbit & $\begin{array}{l}\text { ABIN303468, } \\
\text { Lot \# } 20945\end{array}$ & $\mathrm{CA}$ & $1: 100$ & Antibodies online (Aachen, Germany) \\
\hline MAGE A8 & Rabbit & $\begin{array}{l}(\mathrm{v}-25), \mathrm{sc}-102016 \\
\text { Lot \# G0708 }\end{array}$ & $\mathrm{TR}$ & $1: 30$ & Santa Cruz Biotechnology, Inc. \\
\hline MAGE A9 & Rabbit & $\begin{array}{l}(\mathrm{G}-24), \mathrm{sc}-130811 \\
\text { Lot \# H2010 }\end{array}$ & TR & $1: 10$ & Santa Cruz Biotechnology, Inc. \\
\hline MAGE A10 & Rabbit & $\begin{array}{l}\text { Cat \# PAB4741, } \\
\text { Lot \# SH030124Q }\end{array}$ & TR & $1: 10$ & Abnova \\
\hline MAGE A11 & Rabbit & $\begin{array}{l}(\mathrm{N}-16), \mathrm{sc}-130162, \\
\text { Lot \# I1809 }\end{array}$ & TR & $1: 40$ & Santa Cruz Biotechnology, Inc. \\
\hline MAGE A12 & Rabbit & $\begin{array}{l}\text { Cat \# PAB4743, } \\
\text { Lot \# SA110311AH }\end{array}$ & TR & $1: 10$ & Abnova \\
\hline
\end{tabular}

CA, citric acid (pH 6.0); TR, target retrieval ${ }^{\circledR}(\mathrm{pH} 6.1)$.

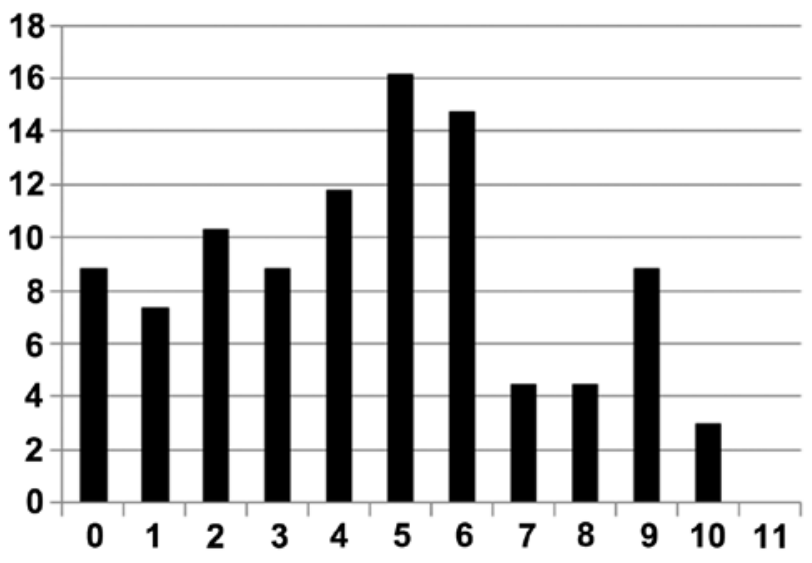

Figure 2. The $\mathrm{x}$-axis shows the number of expressed MAGE-A subtypes within a single tumor specimen. The ordinate represents the percentage of specimens.

temperature, followed by detection using the DAKO Advance+ detection system (DakoCytomation, Pathology Products Dako Deutschland GmbH, Hamburg, Germany) and DAB as the chromogen. The slides were counterstained with hematoxylin and evaluated.

For investigation, the dual system of Remmele and Stegner (25) that was first used in breast cancer was used to evaluate the levels of antigen expression and generate a score [amount of staining (SI): 0, no reaction, 1, weak reaction,
2 , moderately high reaction, 3 , strong reaction; number of positive cells (PP): 0 , negative, $1,<10 \%$ positive cells, $2,10-50 \%$ positive cells, $3,21-80 \%$ positive cells, $4,>80 \%$ positive cells]: SI $x$ PP = Immunoreactive score (IRS).

As different punches of the tumor center and the tumor invasive front were prepared, an IRS (C) for the center, an IRS (F) for the front and an IRS (T) were evaluated. The IRS (T) represents the whole tumor tissue in this study, and its value was determined through summation as follows: $\operatorname{IRS}(\mathrm{T})=\operatorname{IRS}($ total $)=\operatorname{IRS}(\mathrm{C})+\operatorname{IRS}(\mathrm{F})$.

For graphical presentation, IRS (T) has been simplified into four score groups of staining grade $(0$, negative, 1 , weak, 2 , medium and 3 , high).

Statistical analysis of expression rates and clinical parameters was performed with the help of the Department of the Mathematical Branch of the University of Würzburg using Statistica $10^{\circledR}$ (StatSoft, Tulsa, OK, USA) and SPSS $20^{\circledR}$ (IBM, Armonk, NY, USA). Investigation included using the Spearman's correlation, Mann-Whitney U test, Kruskal-Wallis test and Gehan's test. For additional investigation of detailed information within the groups, the post hoc test was applied.

\section{Results}

General expression rates of MAGE-A. Among 68 tumors, $62(91.17 \%)$ had antigen expression of several individual MAGE-A subtypes, and 6 tumors $(8.82 \%)$ had no staining. 
Table III. Comparison of expression in the tumor center and tumor front.

\begin{tabular}{lccccccccccc}
\hline & A1 & A2 & A3 & A4 & A5 & A6 & A8 & A9 & A10 & A11 & A12 \\
\hline P-value & 0.01 & 0.13 & 0.12 & 0.46 & 0.01 & 0.02 & 0.11 & 0.05 & 0.54 & 0.15 & 0.01 \\
Valid cases & $60^{\mathrm{a}}$ & 68 & 68 & 68 & 68 & 68 & 68 & 68 & 68 & 68 & 68 \\
\hline
\end{tabular}

For MAGE-A1, a decreased set of 60 cases were microscopically evaluated due to the first cut of the tissue microarray block, which caused a moderate loss of material during the washing process of the staining procedure.

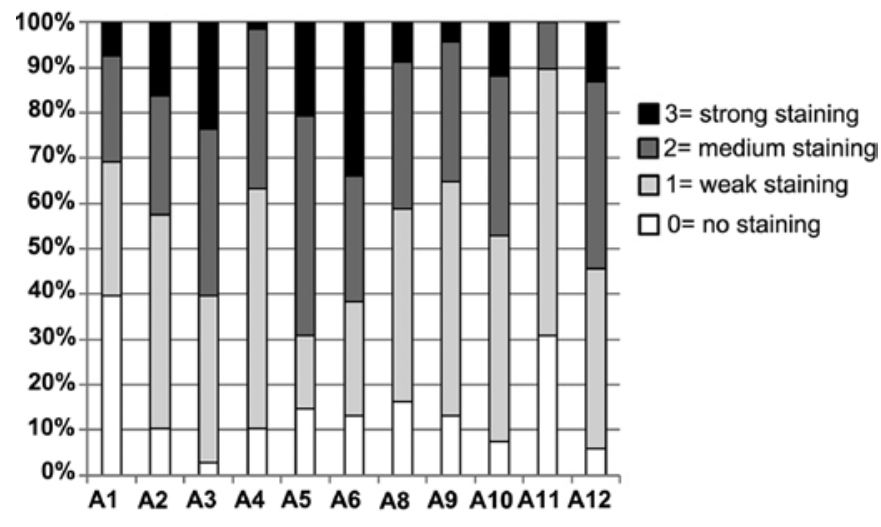

Figure 3. Overall MAGE-A expression in both tumor regions (IRS C + IRS F). The ordinate shows the percentage of stained specimens represented by the respective staining score.

As shown in Fig. 2, 36 tumors (52.94\%) had simultaneous expression of five or more MAGE-A subtypes. Expression of one to four MAGE-A antigens was observed in 26 (38.24\%) specimens. Six tumors $(8.82 \%)$ had no staining for any of the MAGE-A subtypes, as shown in the first column of Fig. 2.

The highest expression rates (summarized through scoring grade 1, 2 and 3) were observed for MAGE-A2 (90\%), -A3 (97\%), -A4 (90\%), -A10 (93\%) and -A12 (94\%).

Statistical investigation of the correlation between expression of five or more antigen subtypes in a single tumor revealed no significant differences in any clinical parameters $(\mathrm{P}>0.05)$.

Expression in the tumor center and tumor invasive front. For MAGE-A1, -A4, -A5, -A6, -A8, -A9, -A10, -A11 and -A12, there was higher expression in the tumor center than in the tumor invasive front. Only MAGE-A2 and -A3 clearly exhibited the opposite behavior as shown in Fig. 4.

Statistical investigation using immunoreactive score [IRS (C)/IRS (F)] showed a significant difference in the expression between the tumor invasive front and tumor center for the MAGE-A subtypes A1, A5, A6, A9 and A12 as shown in Table III. This difference occurred for all of the subtypes with stronger expression in the tumor center. For the other MAGE-A subgroups, the results were not significant.

Correlation of MAGE-A expression with clinical parameters. For correlation of expression with clinical parameters, the overall MAGE-A expression for each subtype was determined and the additional values, represented by IRS (T), were used for statistical analysis.
Age. The study group was divided into 3 groups according to age (1, 35-50 years, 2, 51-70 years and 3, 71-85 years). Within these groups, MAGE-A subtypes were represented by staining score $(0,1,2$ and 3$)$. The highest scores occurred in group 2 (51-70 years), with the exception of MAGE-A10, for which group 3 (71-85 years) had the highest staining scores. Statistical investigation using Spearman's correlation showed no significant results $(\mathrm{P}>0.05)$ for any of the MAGE-A subtypes.

Gender. For MAGE-A1, -A2, -A5, -A6, -A8, -A10 and -A12, higher staining and therefore higher expression occurred in specimens from men, while MAGE-A3, -A4, -A9 and -A11 exhibited the opposite behavior. This result must be regarded differentially because of the small number of female specimens $(n=17)$ in the study. Only MAGE-A1 had significantly higher expression in the whole tumor of male specimens as evaluated by the Mann-Whitney $\mathrm{U}$ test $(\mathrm{P}=0.034)$. In the tumor center, only a trend in the expression of MAGE-A1 for higher grade male specimens was observed $(\mathrm{P}=0.05)$. No other results were significant $(\mathrm{P}>0.05)$.

Tumor size. In this study, we found that for all MAGE-A antigens, the tumors in stage T3 showed the highest expression. Tumors in stage $\mathrm{T} 1$ had less expression than those in stage T2. However, a difference in expression rates was not observed between T3 and T4. Nevertheless, statistical investigation using Kruskal-Wallis test did not show any significant difference between the stages for any of the tested MAGE-A antigens $(\mathrm{P}>0.05)$.

Lymph node status. For MAGE-A1, -A2, -A6, -A8, -A10, -A12, no significant differences were observed between the groups N0, N1 and N2. For MAGE-A3, there was significantly higher expression in the tumor center of tumors with associated lymph node metastasis (N1) compared with those with $\mathrm{N} 0$ status $(\mathrm{P}=0.04)$. Investigation of the overall expression in both regions of the tumor (center and front) revealed significant differences in MAGE-A4 ( $\mathrm{P}=0.02)$, MAGE-A5 $(\mathrm{P}=0.02)$ and MAGE-A9 $(\mathrm{P}=0.02)$ with regards to lymph node stages. For MAGE-A11, a significant difference was only observed for the tumor invasive front $(\mathrm{P}=0.04)$.

Grading. Regarding the grading stage of the tumors, no significant differences between the stage groups and any of the tested MAGE-A antigens were found $(\mathrm{P}>0.05)$.

UICC (Union International Contre le Cancer) stage (disease stage). Only MAGE-A9 expression significantly differed in the invasive tumor front region of the tumors with regards to 


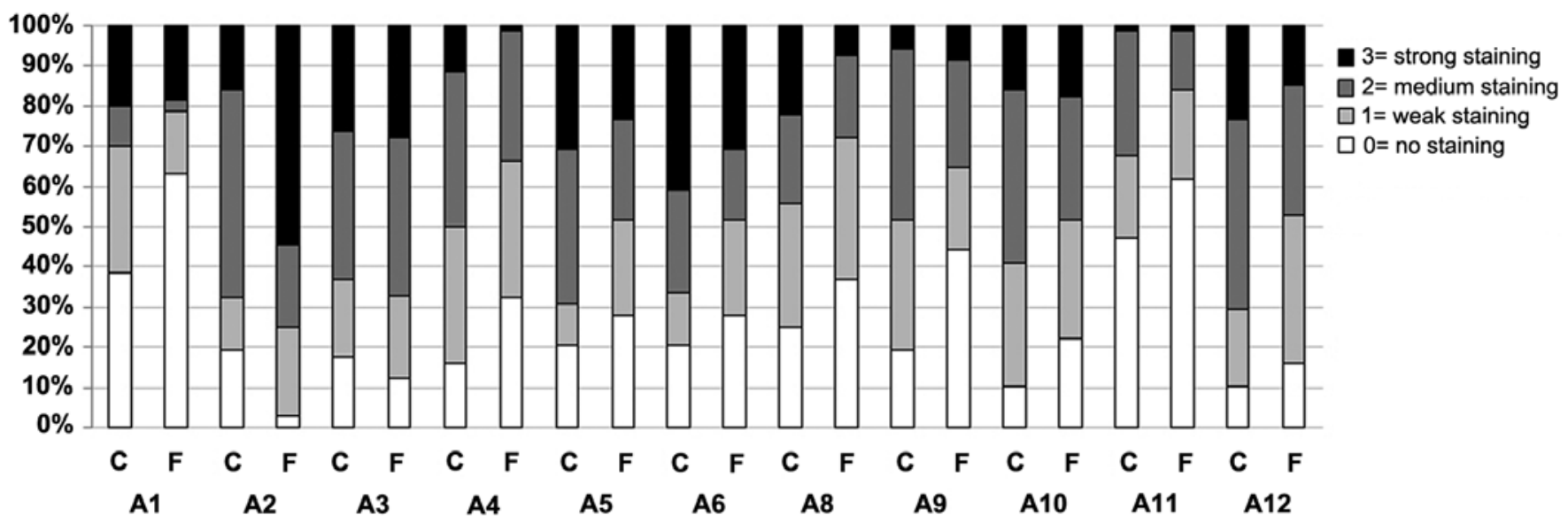

Figure 4. Expression rates for each subtype compared in the tumor center and invasive front (C, center; $F$, invasive front). The fractions of specimens are shown as percentages.

UICC stage $(\mathrm{P}=0.02)$. Detailed post hoc testing showed that the highest significance was between groups I and IV $(\mathrm{P}=0.04)$, which suggests increased malignancy when the expression is elevated.

Survival time. Neither MAGE-A expression nor the expression of five or more antigens were significantly correlated to the survival time. Because of the heterogeneity of the available data, a connection between expression and decreased survival time should not be generally disregarded.

\section{Discussion}

This is the first study to use the expression rates of all MAGE-A subtypes to compare the tumor center and tumor front in OSCC via detailed immunohistochemistry. The study showed that there was expression of MAGE-A antigens in 62 of 68 specimens (91.17\%). Furthermore, 36 of 68 (52.94\%) tumors expressed five or more of the eleven tested antigens. This rate is higher than those previously reported in other studies (14-18).

Comparison of the expression in the tumor center and the invasive front revealed that MAGE-A1, -A4, -A5, -A6, -A8, -A9, -A10, -A11 and -A12 were more highly expressed in the center and that the results were statistically significant for MAGE-A1, -A5, -A6, -A8 and -A12. In contrast, expression was higher in the invasive front for MAGE-A2 and -A3, but this difference was not statistically significant.

Because the invasive front is regarded as the site associated with malignant characteristics such as a higher incidence of p53 mutation, higher levels of Ki-67, more proliferating cells and high epithelial-mesenchymal transition (EMT), our findings are peculiar (20-22). The transition from the somatic cell type to cells with mesenchymal characteristics includes loss of apical-basal polarity, impairment of important cell-cell interactions and therefore higher fragility, higher cell mortality and destabilization of the basal membrane layer $(26,27)$. Because EMT is related to de-differentiation and MAGE-A expressing cells can also exhibit de-differentiation, a relationship between MAGE-A expression and EMT may exist $(28,29)$. Because our results appear to be contrary to those of previous studies, further investigation is needed to clarify the association between EMT and MAGE-A expression at the tumor front and center.

Promoter demethylation and histone deacetylation are regarded as the key steps for inducing MAGE-A expression in tumor cells $(13,30-33)$. However, several authors have also described the absence of CTA expression in tumors with general DNA hypomethylation $(34,35)$.

Moreover, there is an assumption that a necessary 'switching-on' of a gameto-genetic program exists that is derived from germ cell development and leads somatic cells to express CTAs $(30,36)$.

Higher expression of MAGE-A antigens in the tumor center of the specimens in this study group could be explained by this process of reverting back to a developmental stage and augmenting the life span of tumor cells.

However, Aprelikova et al showed a connection between downregulation of MAGE-A11 and a negative influence on hypoxia-inducible factor HIF-1 $\alpha$ in OSCC; HIF-1 $\alpha$ is believed to play a key role in malignant behavior (e.g., resistance to radiotherapy or chemotherapy) of tumor cells with hypoxic surroundings, which are typically found at the center of tumors (37). Moreover, Hartmann et al investigated the negative impact on the effectiveness of therapy for the chemotherapeutics diamindichloridoplatin (DDP) and 5-fluorouracil when high levels of MAGE-A11 were present and found that expression of MAGE-A5 and -A8 resulted in a negative effect on anti-neoplastic therapy including panitumumab treatment $(23,24)$. Interestingly, in our study, the same subgroups have higher expression in the center of the tumor, particularly MAGE-A5. Because the tumor center is the location where so-called 'cancer stem cells' originate and typically proliferate slowly, it is possible that these cells are less practical targets for chemotherapy, which clarifies the frequent occurrence of refractory lapses of the disease (38). These findings clarify the influence of malignant characteristics through the effects of MAGE-A expression on development.

The correlation between patient age and MAGE-A expression was not significant. Nevertheless, the study group with 
the highest staining rates was the patients between 51 and 70 years of age. These findings can be explained by the fact that genomic hypomethylation increases the probability of MAGE-A expression and increasing age promotes this condition $(39,40)$. However, in terms of oral cancer, patients of this age group often present with typical risk factors such as smoking and simultaneous alcoholism, which suggests the potential of a relationship or even a direct interaction between MAGE-A expression with the presence of risk factors.

As was shown significantly for MAGE-A1 as well as for MAGE-A2, -A5, -A6, -A8, -A10 and -A12, male specimens have a tendency to present higher expression rates of CTAs or rather higher staining rates by immunohistochemistry. Because males are much more frequently heavy smokers and drinkers, a direct connection between these risk factors and augmented MAGE-A expression could also be hypothesized.

In addition, tumor size did not significantly correlate with increased MAGE-A expression, as was described in most previous studies. Nevertheless, Müller-Richter et al showed an augmentation of expression rates with the increase of tumor size, and Napoletano et al showed a significant correlation between tumor size of cervical cancer and expression of MAGE-A1,-A2,- A3,-A4,-A6,-A12 using a global MAGE57B antibody $(40,41)$.

However, based on their use of this special global antibody, the studies must be compared and regarded differentially.

Our results showed a correlation of MAGE-A expression with the general presence of lymph node metastasis $\left(\mathrm{N}^{+}\right)$ that was significant for MAGE-A3, -A4, -A5, -A9, and -A11. This correlation did not impact on whether the tumor was stage N1 or N2. Again, the evaluation of Hartmann et al (23) is of interest because they clearly specified that MAGE-A5, -A8 and -A11 are negative predictors of OSCC. The presence of lymph node metastasis normally leads to application of adjuvant therapy, which is often combined with additional chemotherapy $(42,43)$. Therefore, the currently discussed MAGE-A types may represent novel indicators that could lead to more aggressive approaches, even in cases with no positive lymph node status but high expression of certain MAGE-A subtypes. The present study is the first time a significant correlation between MAGE-A expression and further lymph node status in OSCC has been investigated $(15,18)$. Similar results have been reported only for other types of tumors, such as ductal breast, colorectal or gastric cancer (44-46).

Here, significant results for all tests regarding lymph node status were obtained, especially for MAGE-A4. In addition, Forghanifard et al described similar results in their studies for MAGE-A4 in SCC of the esophagus (47). MAGE-A4 was also one of the most expressed subtypes in the present study, and Ries et al (14) showed that MAGE-A4 had the highest expression rates in OSCC.

This difference in expression might represent a reliable tool for the prognosis of OSCC. Moreover, a significantly worse response to the chemotherapeutics docetaxel and paclitaxel occurred for tumors that expressed MAGE-A4, similar to the findings reported by Müller-Richter et al (48). For MAGE-A5, significant results were obtained in general and for the tumor center. Other studies have not yet reported such results in OSCC but have done so for other malignancies, such as lung cancer and colorectal cancer, with comparable findings reported (49). Our non-significant findings regarding tumor grade are in contrast to the results of previous studies by Ries et al (14), Figueiredo et al (17) and Eura et al (11), who described significantly higher malignancy and grading in connection with high MAGE-A expression in their studies of OSCC and head and neck cancers.

Because the 'cancer stem-cell theory' exists and other authors have proposed that only cells with the characteristics of stem cells within a tumor mass are able to express CTAs, de-differentiation could be explained. Literature results regarding the heterogeneity of cells in a tumor and the ability or inability to express antigens should be stressed $(50,51)$.

Correlation studies of UICC stage to expression showed that there was significant expression of MAGE-A9 and a trend for MAGE-A6 in the tumor center. $\mathrm{Gu}$ et al recently found that in HCC, MAGE-A9 expression is an independent prognostic factor for disease-free survival and overall survival and that high MAGE-A9 expression suggests unfavorable survival outcomes in HCC patients (52). In addition, Xu et al recently reported similar results in breast cancer, suggesting that the MAGE-A9 subtype should be regarded as a favorable tool for the evaluation of the prognosis of patients with malignant disease (53). Shigematsu et al showed significantly higher expression of MAGE-A4 in stage II-IV non-small cell lung cancer relative to stage I (54). Because these results only applied to the tumor center, this result also supports the often postulated higher prognostic value of the tumor invasive front $(20-22,55,56)$. Several authors have already described significantly lower 5-year survival rates of patients with certain types of cancers (57-59) that express MAGE-A antigens; therefore, the results of this study have to be considered critically. Investigating larger patient groups may allow us to draw more reliable conclusions.

Although cure rates in OSCC are improving slowly with current therapeutic methods, the present study reveals that MAGE-A3, -A4, -A5, -A9, -A11 are factors that are related to metastatic tendencies and therefore could be used as prognostic tools for improving the follow-up care of patients with OSCC.

\section{References}

1. Barnes L, Eveson JW, Reichart P and Sidransky D (eds): World Health Organization Classification of Tumours: Pathology and Genetics of Head and Neck Tumours. IARC Press, Lyon, 2005.

2. Al-Swiahb JN, Chen CH, Chuang HC, Fang FM, Tasi HT and Chien CY: Clinical, pathological and molecular determinants in squamous cell carcinoma of the oral cavity. Future Oncol 6: 837-850, 2010.

3. Stucken E, Weissman J and Spiegel JH: Oral cavity risk factors: Experts' opinions and literature support. J Otolaryngol Head Neck Surg 39: 76-89, 2010.

4. Folz BJ, Silver CE, Rinaldo A, Fagan JJ, Pratt LW, Weir N, Seitz D and Ferlito A: An outline of the history of head and neck oncology. Oral Oncol 44: 2-9, 2008.

5. Scully C and Bagan JV: Recent advances in Oral Oncology 2007: Imaging, treatment and treatment outcomes. Oral Oncol 44: 211-215, 2008.

6. Jungbluth AA, Busam KJ, Kolb D, Iversen K, Coplan K, Chen YT, Spagnoli GC and Old LJ: Expression of MAGE-antigens in normal tissues and cancer. Int J Cancer 85: 460-465, 2000.

7. Katsura Y and Satta Y: Evolutionary history of the cancer immunity antigen MAGE gene family. PLoS One 6: e20365, 2011.

8. van der Bruggen $\mathrm{P}$, Traversari C, Chomez P, Lurquin C, De Plaen E, Van den Eynde B, Knuth A and Boon T: A gene encoding an antigen recognized by cytolytic $\mathrm{T}$ lymphocytes on a human melanoma. Science 254: 1643-1647, 1991. 
9. van der Bruggen P, Bastin J, Gajewski T, Coulie PG, Boël P, De Smet C, Traversari C, Townsend A and Boon T: A peptide encoded by human gene MAGE-3 and presented by HLA-A2 induces cytolytic $\mathrm{T}$ lymphocytes that recognize tumor cells expressing MAGE-3. Eur J Immunol 24: 3038-3043, 1994.

10. Lee KD, Eura M, Ogi K, Nakano K, Chikamatsu K, Masuyama K and Ishikawa T: Expression of the MAGE-1, $-2,-3,-4$, and -6 genes in non-squamous cell carcinoma lesions of the head and neck. Acta Otolaryngol 116: 633-639, 1996.

11. Eura M, Ogi K, Chikamatsu K, Lee KD, Nakano K, Masuyama K, Itoh $\mathrm{K}$ and Ishikawa T: Expression of the MAGE gene family in human head-and-neck squamous-cell carcinomas. Int J Cancer 64: 304-308, 1995.

12. Barker PA and Salehi A: The MAGE proteins: Emerging roles in cell cycle progression, apoptosis, and neurogenetic disease. J Neurosci Res 67: 705-712, 2002.

13. Simpson AJ, Caballero OL, Jungbluth A, Chen YT and Old LJ: Cancer/testis antigens, gametogenesis and cancer. Nat Rev Cancer 5: 615-625, 2005

14. Ries J, Schultze-Mosgau S, Neukam F, Diebel E and Wiltfang J: Investigation of the expression of melanoma antigen-encoding genes (MAGE-A1 to -A6) in oral squamous cell carcinomas to determine potential targets for gene-based cancer immunotherapy. Int J Oncol 26: 817-824, 2005.

15. Ries J, Vairaktaris E, Mollaoglu N, Wiltfang J, Neukam FW and Nkenke E: Expression of melanoma-associated antigens in oral squamous cell carcinoma. J Oral Pathol Med 37: 88-93, 2008.

16. Kienstra MA, Neel HB, Strome SE and Roche P: Identification of NY-ESO-1, MAGE-1, and MAGE-3 in head and neck squamous cell carcinoma. Head Neck 25: 457-463, 2003

17. Figueiredo DL, Mamede RC, Proto-Siqueira R, Neder L, Silva WA Jr and Zago MA: Expression of cancer testis antigens in head and neck squamous cell carcinomas. Head Neck 28 : 614-619, 2006

18. Montoro JR, Mamede RC, Neder Serafini L, Saggioro FP Figueiredo DL, Silva WA Jr, Jungbluth AA, Spagnoli GC and Zago MA: Expression of cancer-testis antigens MAGE-A4 and MAGE-C1 in oral squamous cell carcinoma. Head Neck 34 1123-1128, 2012.

19. Cuffel C, Rivals JP, Zaugg Y, Salvi S, Seelentag W, Speiser DE, Liénard D, Monnier P, Romero P, Bron L, et al: Pattern and clinical significance of cancer-testis gene expression in head and neck squamous cell carcinoma. Int J Cancer 128: 2625-2634, 2011.

20. Piffkò J, Bànkfalvi A, Tory K, Füzesi L, Bryne M, Ofner D, Kusch F, Joos U and Schmid KW: Molecular assessment of p53 abnormalities at the invasive front of oral squamous cell carcinomas. Head Neck 20: 8-15, 1998.

21. Horta MC, de Assis LA, de Souza AF, de Araújo VC, Gomez RS and Aguiar MC: p53 and p21 ${ }^{\mathrm{WAF} / \mathrm{CIP} 1}$ overexpression at the invasive front of lower lip squamous cell carcinoma. J Oral Pathol Med 36: 88-92, 2007.

22. Tumuluri V, Thomas GA and Fraser IS: The relationship of proliferating cell density at the invasive tumour front with prognostic and risk factors in human oral squamous cell carcinoma. J Oral Pathol Med 33: 204-208, 2004.

23. Hartmann S, Kriegebaum U, Küchler N, Brands RC, Linz C, Kübler AC and Müller-Richter UD: Correlation of MAGE-A tumor antigens and the efficacy of various chemotherapeutic agents in head and neck carcinoma cells. Clin Oral Investig 18: 189-197, 2014.

24. Hartmann S, Kriegebaum U, Küchler N, Lessner G, Brands RC, Linz C, Schneider T, Kübler AC and Müller-Richter UD: Efficacy of cetuximab and panitumumab in oral squamous cell carcinoma cell lines: Prognostic value of MAGE-A subgroups for treatmen success. J Craniomaxillofac Surg 41: 623-629, 2013.

25. Remmele W and Stegner HE: Recommendation for uniform definition of an immunoreactive score (IRS) for immunohistochemical estrogen receptor detection (ER-ICA) in breast cancer tissue. Pathologe 8: 138-140, 1987 (In German).

26. Thiery JP: Epithelial-mesenchymal transitions in tumour progression. Nat Rev Cancer 2: 442-454, 2002.

27. Yang CC, Zhu LF, Xu XH, Ning TY, Ye JH and Liu LK: Membrane type 1 matrix metalloproteinase induces an epithelia to mesenchymal transition and cancer stem cell-like properties in SCC9 cells. BMC Cancer 13: 171, 2013

28. Thiery JP: Epithelial-mesenchymal transitions in development and pathologies. Curr Opin Cell Biol 15: 740-746, 2003.

29. Kalluri R and Weinberg RA: The basics of epithelial-mesenchymal transition. J Clin Invest 119: 1420-1428, 2009.
30. Caballero OL and Chen YT: Cancer/testis (CT) antigens: Potential targets for immunotherapy. Cancer Sci 100: 2014-2021, 2009.

31. Karpf AR, Bai S, James SR, Mohler JL and Wilson EM: Increased expression of androgen receptor coregulator MAGE-11 in prostate cancer by DNA hypomethylation and cyclic AMP. Mol Cancer Res 7: 523-535, 2009.

32. Scanlan MJ, Gure AO, Jungbluth AA, Old LJ and Chen YT: Cancer/testis antigens: An expanding family of targets for cancer immunotherapy. Immunol Rev 188: 22-32, 2002.

33. Wischnewski F, Pantel K and Schwarzenbach H: Promoter demethylation and histone acetylation mediate gene expression of MAGE-A1, -A2, -A3, and -A12 in human cancer cells. Mol Cancer Res 4: 339-349, 2006.

34. Wang Z, Zhang J, Zhang Y, Srivenugopal KS and Lim SH: SPAN-XB core promoter sequence is regulated in myeloma cells by specific $\mathrm{CpG}$ dinucleotides associated with the MeCP2 protein. Int J Cancer 119: 2878-2884, 2006.

35. Lim SH, Zhang Y and Zhang J: Cancer-testis antigens: The current status on antigen regulation and potential clinical use. Am J Blood Res 2: 29-35, 2012.

36. Old LJ: Cancer/testis (CT) antigens - a new link between gametogenesis and cancer. Cancer Immun 1: 1, 2001.

37. Aprelikova O, Pandolfi S, Tackett S, Ferreira M, Salnikow K, Ward Y, Risinger JI, Barrett JC and Niederhuber J: Melanoma antigen-11 inhibits the hypoxia-inducible factor prolyl hydroxylase 2 and activates hypoxic response. Cancer Res 69: 616-624, 2009.

38. Patel SS, Shah KA, Shah MJ, Kothari KC and Rawal RM: Cancer stem cells and stemness markers in oral squamous cell carcinomas. Asian Pac J Cancer Prev 15: 8549-8556, 2014.

39. Liu L, Wylie RC, Andrews LG and Tollefsbol TO: Aging, cancer and nutrition: The DNA methylation connection. Mech Ageing Dev 124: 989-998, 2003.

40. Müller-Richter UD, Dowejko A, Peters S, Rauthe S, Reuther T, Gattenlöhner S, Reichert TE, Driemel $O$ and Kübler AC: MAGE-A antigens in patients with primary oral squamous cell carcinoma. Clin Oral Investig 14: 291-296, 2010.

41. Napoletano C, Bellati F, Tarquini E, Tomao F, Taurino F, Spagnoli G, Rughetti A, Muzii L, Nuti M and Benedetti Panici P: MAGE-A and NY-ESO-1 expression in cervical cancer: Prognostic factors and effects of chemotherapy. Am J Obstet Gynecol 198: 99.e1-7, 2008.

42. Kreppel M, Drebber U, Eich HT, Dreiseidler T, Zöller JE, Müller RP and Scheer M: Combined-modality treatment in advanced oral squamous cell carcinoma: Primary surgery followed by adjuvant concomitant radiochemotherapy. Strahlenther Onkol 187: 555-560, 2011.

43. Adelstein DJ, Lavertu P, Saxton JP, Secic M, Wood BG, Wanamaker JR, Eliachar I, Strome M and Larto MA: Mature results of a phase III randomized trial comparing concurrent chemoradiotherapy with radiation therapy alone in patients with stage III and IV squamous cell carcinoma of the head and neck. Cancer 88: 876-883, 2000.

44. Kavalar R, Sarcevic B, Spagnoli GC, Separovic V, Samija M, Terracciano L, Heberer M and Juretic A: Expression of MAGE tumour-associated antigens is inversely correlated with tumour differentiation in invasive ductal breast cancers: An immunohistochemical study. Virchows Arch 439: 127-131, 2001.

45. Li M, Yuan YH, Han Y, Liu YX, Yan L, Wang Y and Gu J: Expression profile of cancer-testis genes in 121 human colorectal cancer tissue and adjacent normal tissue. Clin Cancer Res 11: 1809-1814, 2005

46. Jung EJ, Kim MA, Lee HS, Yang HK, Lee YM, Lee BL and Kim WH: Expression of family A melanoma antigen in human gastric carcinoma. Anticancer Res 25: 2105-2111, 2005.

47. Forghanifard MM, Gholamin M, Farshchian M, Moaven O, Memar B, Forghani MN, Dadkhah E, Naseh H, Moghbeli M, Raeisossadati $\mathrm{R}$, et al: Cancer-testis gene expression profiling in esophageal squamous cell carcinoma: Identification of specific tumor marker and potential targets for immunotherapy. Cancer Biol Ther 12: 191-197, 2011.

48. Müller-Richter UD, Dowejko A, Driemel O, Reuther T, Reichert TE and Kübler AC: Impact of MAGE-A antigens on taxane response in oral squamous cell carcinoma. Oncol Lett 1: 181-185, 2010.

49. Kim YD, Park HR, Song MH, Shin DH, Lee CH, Lee MK and Lee SY: Pattern of cancer/testis antigen expression in lung cancer patients. Int J Mol Med 29: 656-662, 2012.

50. Zajicek G: Neoplasia - a stem cell pathology. Med Hypotheses 13: $125-136,1984$ 
51. Costa FF, Le Blanc K and Brodin B: Concise review: Cancer/testis antigens, stem cells, and cancer. Stem Cells 25: 707-711, 2007.

52. Gu X, Fu M, Ge Z, Zhan F, Ding Y, Ni H, Zhang W, Zhu Y, Tang X, Xiong L, et al: High expression of MAGE-A9 correlates with unfavorable survival in hepatocellular carcinoma. Sci Rep 4: 6625, 2014.

53. Xu X, Tang X, Lu M, Tang Q, Zhang H, Zhu H, Xu N, Zhang D, Xiong L, Mao Y, et al: Overexpression of MAGE-A9 predicts unfavorable outcome in breast cancer. Exp Mol Pathol 97: 579-584, 2014

54. Shigematsu Y, Hanagiri T, Shiota H, Kuroda K, Baba T, Mizukami M, So T, Ichiki Y, Yasuda M, So T, et al: Clinical significance of cancer/testis antigens expression in patients with non-small cell lung cancer. Lung Cancer 68: 105-110, 2010.

55. Bryne M, Koppang HS, Lilleng R and Kjaerheim A: Malignancy grading of the deep invasive margins of oral squamous cell carcinomas has high prognostic value. J Pathol 166: 375-381, 1992.
56. Piffkó J, Bánkfalvi A, Ofner D, Kusch F, Böcker W, Joos U and Schmid KW: In situ assessment of cell proliferation at the invasive front of oral squamous cell carcinomas. Virchows Arch 429: 229-234, 1996.

57. Pastorcic-Grgic M, Sarcevic B, Dosen D, Juretic A, Spagnoli GC and Grgic M: Prognostic value of MAGE-A and NY-ESO-1 expression in pharyngeal cancer. Head Neck 32: 1178-1184, 2010.

58. Suzuki S, Sasajima K, Sato Y, Watanabe H, Matsutani T, Iida S, Hosone M, Tsukui T, Maeda S, Shimizu K, et al: MAGE-A protein and MAGE-A10 gene expressions in liver metastasis in patients with stomach cancer. Br J Cancer 99: 350-356, 2008.

59. Metzler P, Mollaoglu N, Schwarz S, Neukam FW, Nkenke E and Ries J: MAGE-A as a novel approach in the diagnostic accuracy of oral squamous cell cancer: A case report. Head Neck Oncol 1: 39, 2009. 